Journal of Development and Communication Studies, Vol. 8. No. 1, January -June, 2021 ISSN (Online \& Print): 2305-7432. http://www.devcomsjournalmw.org

\title{
Narrative Persuasion: Moderating effects of character identification on relationship between message format and intention to screen for cervical cancer among women in agricultural sector in Kiambu County, Kenya.
}

Joseph Muchiri, School of Public Health, Mount Kenya University Email: mutitu.muchiri@gmail.com, Helen Mberia, School of Communication, Jomo Kenyatta University \& Ryoidah Nyambane, Technical University of Kenya.

\begin{abstract}
There is evidence that use of narrative messages is effective in the context of health behavior change. There is however no explanation as to what aspect of narrative leads to high level of persuasion. We evaluated the moderating effects of character identification on the three elements of narrative message (narrative message frame, narrative rationality and narrator's perspective) in regard to the uptake of cervical cancer screening among women in the agricultural sector in Kiambu county, Kenya. A randomised experimental design was used. Narrative Message frame (gain frame vs. loss frame), narrative perspective (first vs third person), and narrative rationality, were manipulated. The messages were presented via a brief narrative video on cervical cancer and cervical screening. A uniform pretest questionnaire on cervical cancer and cervical cancer screening (T1) was completed by respondents before watching a narrative video. After watching a narrative video on cervical cancer screening, participants responded to the post test questionnaire (T2). Data from 378 (100 per cent) respondents for the pretest and 344 (91 per cent) for posttest was analysed and included in the study findings for the baseline and posttest respectively. Multiple hierarchical regression analysis was used. The study found that the majority of respondents were aged above 41 years of age at 32 per cent majority 249 (65.9 per cent) of the respondents were married, and majority 210 (55 per cent) of the respondents had 1 to 3 children followed by 4 to 5 at 91 (24 per cent). After running multiple hierarchical regression analysis, the study found that identification with story character moderated for all the independent variables. The study concluded that while using narrative messages to promote health behaviour, use of story
\end{abstract}


characters which the target audience can identify with, may help in increasing adoption of advocated health behaviour.

\section{Key words}

Narrative communication, cervical cancer, character identification, moderation analysis

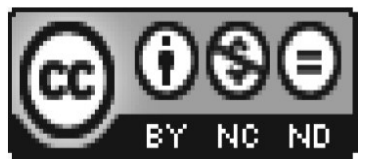

(C) 2020. The author. This work is licensed under the Creative Commons Attribution 4.0 International License (CC-By-NC-ND). Users may freely share and redistribute this work provided that the author and the Journal of Development and Communication Studies are fully acknowledged. Users may not tweak or remix and offer this work for sale. The full license may be accessed at https://creativecommons.org/licenses/by-nc-nd/4.0/

To cite this article: Muchiri, J. (2021). Narrative Persuasion: Moderating effects of Character identification on relationship between message format and intention to screen for cervical cancer among women in agricultural sector in Kiambu County, Kenya. Journal of Development and Communication Studies, 8(1), 164 - 184 https://dx.doi.org/10.4314/jdcs.v8i1.8

\section{Introduction}

Cervical cancer is one of the most frequently diagnosed form of cancers in women. In 2018, approximately 570,000 cases and 311,000 deaths was reported globally (Buskwofie, 2020). The majority of the cases occurred in developing countries (de Martel et al., 2017). With increased awareness on prevention, effective screening, timely diagnosis and treatment, most of these deaths could be prevented. According to a study conducted by Denny (2010), 60 to 90\% reduction of cervical cancer mortality rates could be experienced within three years of implementation of cervical cancer screening programmes in rural populations.

In Kenya cervical cancer screening tests are offered for free and are available at most health facilities ("Kenya National Cancer Screening Guidelines," 2018). However, in spite of this, the uptake of these services is generally low. In 2018, the Kenya's national coverage for cervical cancer screening was estimated to be at $3.2 \%$ for all women, $4.0 \%$ for women in urban areas, and $2.6 \%$ for women in rural areas (Morema et al. , 2014a). A variety of reasons have been given for low uptake of cervical cancer screening services. These includes user fees, time required to effectively consume the service, danger associated with the test, stigma, embarrassment, poor knowledge, among others things (Saraiya et al., 2017) .

The implication of this low uptake of cervical cancer screening services is that most of the patients do not get to know their cervical cancer status early, and consequently present at health facilities when the disease has progressed to advanced 
stages, when it is difficult to manage. Patients with advanced cervical cancer usually have poor treatment outcomes and more than half of these die (Santesso et al., 2016).

One of the most notable interventions in the up scaling uptake of cervical screening is the use of efficient cancer communication strategies (Wojcieszak \& N Kim, 2016). Moreover, Elbert et al. (2017), have shown that communicating messages in a manner that is friendly and in formats the message recipients can relate to often lead to a higher adoption and maintenance of health behaviour (Elbert, Dijkstra, \& Rozema, 2017).

There is evidence that use of narrative messages is effective in the context of health behavior change. For example, a study by Yoo et al. (2015) showed narrative to be effective in decreasing turning bed use, (Yoo et al., 2014; Nanet et al. 2015, Wojcieszak \& Kim 2016; Chen et al. 2016), promoting blood donation (Kopfman, Smith, Yun, \& Hodges, 1998), in increase donation of organ (Weber, Martin, \& Corrigan, 2006), encouraging the consumption of fruit and vegetables (Slater et al., 2003), and avoiding tendency for drunk driving (Stitt \& Nabi, 2005).

While literature has it that narratives are effective in promoting health behaviour, it is not entirely known what precise parts of narrative message format influence higher perception of threat and effectiveness and ultimately lead to intention to engage in the recommended health behaviour (Green, 2008).

Green and Brock (2001) have suggested that persuasion is a function of transportation into the narrative world. According to Carr (1997), narrative world is an imagery world conceived in the mind of the narrative observer as he observes (listen) to the narrative. The mechanism of transportation, the study suggests, is through several pathways including creation of emotional responses, connection with character through character identification, and by making narrative look more similar to the real world experience. They, however, do not offer any explanation as to what elements of narrative message construction lead to transportation into the narrative world in the first place, and consequently leading to persuasion. Following this discussion, therefore, the important problem of what particular element of narrative messages leads to persuade an individual to adopt a health behaviour remains unexplored. In this regard, this study hypothesised that interaction of narrative characteristics (narrative message frame, narrative rationality and narrator's perspective) with story character (character identification) transports the listener into the narrative world and triggers behavioural change.

This study, therefore, evaluated the moderating effects of character identification on the three elements of narrative message (narrative message frame, narrative rationality and narrator's perspective) in regard to the uptake of cervical cancer screening among women in the agricultural sector in Kiambu county, Kenya. To achieve this, the study had three null hypotheses, thus: 
Ho:: Character identification has no significant moderating effects on message frames in regard to screening for cervical cancer among women in the agricultural sector in Kiambu County, Kenya.

Ho2: Character identification has no significant moderating effects on narrative perspective in regard to screening for cervical cancer among women in the agricultural sector in Kiambu County, Kenya.

Ho3: Character identification has no significant moderating effects on narrative rationality in regard to screening for cervical cancer among women in the agricultural sector in Kiambu County, Kenya.

\section{Methodology}

A randomised experimental design was used. Narrative Message frame (gain frame vs. loss frame) was manipulated. The messages was presented via a medium of a brief narrative video on cervical cancer and cervical screening. A uniform pretest questionnaire on cervical cancer and cervical cancer screening (T1) was completed by respondents before watching a narrative video. After watching a narrative video on cervical cancer screening participants responded to the post test questionnaire (T2). The post test questionnaire had similar items as in the pretest questionnaire but in addition, it had items evaluating the believability of the narrative (Yale, 2013) and identification with the character in the story (Igatua, 2010).

This study had four arms including 1) loss framed narrative message arm in the first person perspective, 2) loss framed narrative message arm in the third person perspective ; 3) gain framed narrative message arm in the first person perspective ; and 4) gain framed narrative message arm in the third person perspective. Loss framed messages described the negative experiences of a victim of cervical cancer and gain framed message emphasised the positive experiences of a person who had cervical cancer detected early through screening and therefore positive treatment outcomes with little adverse experiences.

Message video in the first-person video utilised first-person pronouns (i.e., I and me) and messages video in the third-person utilised third-person pronouns (i.e., she and her). A uniform pretest questionnaire (T1) was administered to all the participants in the four groups. Participants were randomly assigned to one of the four experimental conditions.

The study was carried out in Tea firms in Kiambu County. For an estate to be included in the study, it needed to meet the eligibility criteria which included having an average of 30 employees, having a well-established Human Resource Department, and express authorisation for the study to be carried out from the management. This population was selected for the study due to the fact that the uptake of cervical cancer screening is lower in rural areas than in urban settings. As noted earlier, in rural areas 
of Kenya, cervical cancer screening coverage is estimated to be at $2.6 \%$ against urban setting of $4 \%$. The government's target coverage is $70 \%$ (Morema et al, 2014). Kiambu was selected due to the fact that cervical cancer is one of the leading causes of morbidity and mortality among women within reproductive age (Ministry of Health, 2017). In spite of this, the uptake of cervical cancer in the county is among the lowest. According to the County Annual Development Plan (2019), the population of women between 20 to 64 years of age in Kiambu was estimated to be 614,412. Out of this, less than 22000 (3.5\%) had been screened for cervical cancer (County Annual Development plan 2019-2020).

This study targeted women aged 20 to 64 years working in Tea and Coffee estates in Kiambu County for two reasons. First, it is the age interval in which cervical cancer screening is most cost effective (Fonthom et al, 2020), and it is the age interval in which individual are most sexually active, and, therefore, at high risk of infection with Human Papiloma Virus, a causative agent of cervical cancer (WHO, 2015).

Four Tea firms were included in the study. These included Gakoe tea estate, Karirana tea estate, Matara tea factory Gachege tea factory. The four tea firms were randomly picked from a list of 14 tea firms obtained from crop officer Kiambu County. The sampling frame comprised a list of women working in these firms obtained from Human Resource departments in the estates. A further filtering was done on the list so that only individual females who met the inclusion criteria (female aged 2064years) were identified for further sampling to participate in the study. Women in all roles in the industry including tea pickers, factory workers, administration, and management were included as long as they met the 20-64 years inclusion inclusion criteria A sample of 378 respondents was used in the study.

The sample was allocated in such a way that each of the four study arms had 94 respondents. Upon receipt of the list of employees from human resource, it was vetted to ensure that only individual women who met the 20-64 years of age inclusion criteria were selected for random allocation into the study arms. Individuals in the list were given serial numbers and using the serial number random numbers were generated using SPSS. The selected individuals were assigned to the four study arm.

The study used purposive technique to select Kiambu County, and simple random sampling in the selection of tea firms and study participants. Kiambu County was purposively selected for the study due to the fact that it has a high mortality related to cervical cancer (Morgan, 2018), has low cervical cancer screening coverage (cervical cancer screening is below 2.6\%) and due to County's agricultural orientation. Selection of Tea estates was Random. A list of all tea estate was obtained from the County crop officer to act as sampling frame. Finally, respondents were randomly selected and randomly allocated in the study arms. A list of eligible female employees was obtained from the HR departments of each of the Estate and used sampling frame and random allocation in to the four arms done. 
The messages was presented via a video clip on cervical cancer and cervical screening. The intervention arm consisted of narrative video clips depicting personal stories of cervical cancer survivors. Four narrative video formats were created. The first the video message emphasised the benefits that the survivor had as a result of taking up a cervical screening services (gain framed message). The second video message was about the negative experiences the narrator had as result of discovering cancer late (loss framed message). The third was on the benefits that the survivor had as a result of taking up a screening service. However, this was in the third person (gain -framed message third person narrative). The fourth video was on the negative experiences the narrator had as result of discovering cancer late, but in the third person narrative (loss -framed message third person narrative).

The narrator in the loss framed message video clip was a real cancer survivor who successfully underwent cancer treatment at the AMPATH oncology institute cancer program (Moi University). The cancer survivor in the loss framed video clip was volunteered to participate in the study. On the other hand Gain framed video clip was recorded from a woman who had an early cervical screen and benefited from the screening were emphasised. Moreover, both third person gain and loss framed video clips were based on the first person gain and loss video clips.

Two types of questionnaire were administered. A uniform pretest questionnaire with items on cervical cancer and cervical cancer screening (T1) was completed by respondents before watching any of the narrative video clips. The pretest questionnaire had items on socio-demographic characteristic, items on knowledge on cervical cancer, items on cervical cancer risk perception, and items on intention to screen for cervical cancer. The post test (T2) questionnaire had all the above items but in addition it had items on narrative rationality and character identification. Apart from items on socio-demographic characteristics, all other items were Likert scale items with a scale of 1 to 5 where 1 represented 'strongly disagreed' and 5 represented 'strongly agree'.

Items on knowledge on cervical cancer and cervical cancer screening, perceived risk and perceived threat susceptibility, perceived self-efficacy and perceived response efficacy were measured using an adaptation of items scale from several authors including Witte et al.'s (1998) 5-item scale, Luszczynska et al. (2010), and Sherer, (1982). Intentions to engage in the recommended cervical cancer screening behaviour change was measured using a 7-item scale adopted and modified from work by (Yoon, 2016).

The Posttest (T2) questionnaire sought to measure change in respondents' response in all of the above pretest questionnaire content after watching any one of the video clips. In addition, two additional variables were measured including character identification and narrative rationality. Identification with characters was measured using an adaptation of Igartua and Paez's (2010) 14-item scale. 
Participants were asked to indicate the degree to which they agreed or disagreed with statements such as, "I thought I was like the character or very similar to her" and "I understood the characters' feelings or emotions" on a 5-point Likerttype scale $(1=$ strongly disagree to $5=$ strongly agree $)$.

Finally, narrative rationality was measured by adaptation of Yale (2013) narrative believability (rationality) scale. Narrative rationality is the extent to which a story is coherent, consistent and fits to the story observers experiences in day to day experience (Daiton, 2017). The scale has 12 items covering six aspects of narrative rationality including, coherence, fidelity, plausibility, completeness, consistency, and coverage. Participants were asked to indicate the degree to which they agreed or disagreed with specific assertions in the scale on a 5-point Likert-type scale (1= strongly disagree to $5=$ strongly agree).

Piloting was done in two tea estates of in Kericho, Kenya (Kaisugu and James Finlay) in December 2019 to identify potential gaps in the research tools as well as to measure the internal consistency of the study tool. Further, the tool's reliability and validity were measured during the pilot test. Based on Connelly (2008) recommendation that $10 \%$ of the sample projected for the larger parent study is sufficient for a pilot study, the study included 37 respondents for the pilot study. These were equally distributed in the two pilot study sites.

Both types of questionnaire were administered. Loss frame first person video clip was used for pilot study. A uniform pretest questionnaire on cervical cancer and cervical cancer screening (T1) was completed by the respondents before watching the video clips. Then after watching the video clip, participants responded to a brief posttest questionnaire (T2). Items found to be problematic were adjusted.

For the variable Narrative rationality, there were 12 items. For the variable, the alpha coefficient recorded was 0.84 which was above 0.6. required. All items had alpha coefficients above 0.6. Consequently no items was removed from the series. Regarding character identification the alpha coefficient was 0.74 and again no item was expunged from the list. In respect to items on knowledge on cervical cancer and cervical cancer screening the alpha coefficient was 0.82. All the items were retained. Finally, in regard to behavioural intention variable, the Cronbach's alpha coefficient was 0.74 with all the items being retained.

Following the pilot study, the data was collected, cleaned, coded and entered into Statistical Package for Social Science (IBM SPSS version 21) computer software. Both descriptive and inferential statistics were used to analyse the data. The initial stage of descriptive statistics consisting of frequencies, percentages, and means were used to summarise observations on variables measuring socio-demographic characteristics, knowledge in regard to cervical cancer and cervical cancer screening, risk perception on cervical cancer, and the intention to screen for cervical. Hierarchical Multiple Regression were used with inferential statistics. 


\section{Study findings}

A 100 percent response rate was achieved for the baseline study. However, there were some item non response in cases where some respondents opted not respond to some items in the questionnaire, resulting to some missing data. This was addressed substituting the missing data with series means (Ehrlinger et al, 2018). In the posttest, 34 respondents were lost to follow up resulting to a response rate of $91 \%$ (344). Consequently, data from $378(100 \%)$ respondents for the pretest and $344(91 \%)$ for posttest, was analysed and included in the study findings for the baseline and posttest respectively

The majority of the respondents were aged above 41 years of age at $32 \%$. This was followed by respondents aged between 31 to 35 and 36 to 45 years of age, at $27.5 \%$ and $20.5 \%$. Combined, the two groups accounted for $48 \%$ of all the respondents. Regarding whether there was a statistically significant difference among the age groups in respect to cervical cancer screening status, Chi test returned a no statistically significant results $X^{2}(4, \mathrm{~N}=378)=3.886, \mathrm{p}=0.442$.

Most respondents ( 249 or $65.9 \%$ ) were married. Chi square test to determine if there existed a statistically significant difference in regard to screening status of the respondents across marital status returned a no significant Chi test result $X^{2}(5, N=378)=5.88, p=0.432$. Only a small proportion of respondents $70(18.4 \%)$ had attained secondary and tertiary education. This may have an implication in regard to uptake of cervical cancer screening services as people with poor education may also have poor knowledge on need for cervical cancer screening. Chi square test to find if the number of women who had screened for cervical cancer was statistically significant different across the level of education returned a significant $C$ hi test results $X^{2}(5, N=378)=5.88, p=0.432$. The majority of the respondents $227(60.1 \%)$ in the study were protestants followed by Catholics at 137 (36\%). Only 5(1.3\%) respondents declared that they did not belong to any religion. Chi square test to determine whether there was statistical association in respect to having screened for cervical cancer across religions returned a significant $X^{2}(1, N=378)=10.26, p=0.001$.

Finally regarding parity, most (210 or 55\%) of the respondents had 1 to 3 children followed by 4 to 5 at $91(24 \%)$. Together, these two groups, accounted for over $75 \%$ of all the respondents. Chi square test to determine if there exist a statistically significant difference between the respondents with low parity ( 1 to 3 children) and high parity ( above three children) in regard to their screening status returned a significant test results $X^{2}(3, N=378)=18.846, p=0.000$. Those with three and fewer children were less likely to have screened for cervical cancer compared to those who had more than three children. 


\section{Hypothesis testing}

Ho: Character identification has no significant moderating effects on message frames in regard to screening for cervical cancer among women in the agricultural sector in Kiambu County, Kenya.

To determine the moderating effects of character identification on message frame, a hierarchical multiple regression analysis was performed. The outcome variable of analysis was intention to screen for cervical cancer, the predictor variable for the analysis was message frame, and the moderator variable evaluated for the analysis was character identification. Moreover, social demographic variables were controlled for in the model.

In so doing, sociodemographic variables were entered in block 1, message frame was entered in the block 2 and interaction term between the message frame and character identification was entered in the block 3 . The results were as indicated in the multiregression analysis table 2 below.

\section{Table 2 Hierarchical Multiple Regression analysis of moderating effects of character} identification on narrative rationality

$\begin{array}{lrrrrrr}\text { Variable } & \beta & \mathrm{t} & \mathrm{sr}^{2} & \mathrm{R} & \mathrm{R}^{2} & \Delta \mathrm{R}^{2} \\ \text { Step 1 } & & & & \mathbf{0 . 1 3 4} & \mathbf{0 . 0 1 8} & \mathbf{0 . 0 1 8} \\ \text { Marital status } & 0.075 & -1.382 & 0.075 & & & \\ \text { Religion of the respondents } & 0.093 & 1.705 & 0.092 & & & \\ \text { Highest Education level } & .011 & .205 & 0.011 & & & \\ \text { age } & -.046 & -.830 & 0.045 & & & \\ \text { Step 2 } & & & & \mathbf{0 . 3 3 9} & \mathbf{0 . 1 1 5} & \mathbf{0 . 0 9 7} \\ \text { age } & -.081 & -1.570 & 0.085 & & & \\ \text { Religion of the respondents } & .096 & 1.870 & 0.101 & & & \\ \text { Education level } & -.025 & -.467 & 0.025 & & & \\ \text { Marital status } & -.029 & -.559 & 0.030 & & & \\ \text { Message frame } & -.314 & 6.079 & 0.314 & & & \\ \text { Step 3 } & & & & \mathbf{0 . 3 5 0} & \mathbf{0 . 1 2 3} & \mathbf{0 . 0 0 8} \\ \text { age } & -.214 & .690 & -.026 & & & \\ \text { Religion of the respondents } & 1.087 & 1.729 & 0.100 & & & \\ \text { Education level } & 0.33 & -0.093 & -.025 & & & \\ \text { Marital status } & 0.296 & -1.088 & -092 & & & \\ \text { Message frame } & -.1501 & -5.14 & .210 & & & \\ \text { MF* character ID Interaction term }= & .046 & 1.724 & .094 & & & \\ \text { narrative rationality and character } & & & & & & \\ \text { identification interaction term } & & & & & & \end{array}$


Note ${ }^{*} \mathrm{MF}^{*}$ character ID Interaction term $=$ narrative rationality and character identification interaction term

The socio demographic variables entered in the first step accounted for $1.8 \%$ of variation on intention to screen for cervical cancer. This change was, however, not significant $\left(\mathrm{R}^{2}=0.018, \mathrm{~F}(4,344)=1.98, \mathrm{p}=0.192\right.$. Adding message frame to the model the change in $\mathrm{R}^{2}$ went up from 0.08 to 0.115 . At step 2 , therefore, the model accounted for $11.5 \%$ of intention to screen for cervical cancer. This change was significant $\mathrm{R}^{2}=$ $0.115, \mathrm{~F}(5,339)=8.749, \mathrm{p}=0000$. The interaction term was added at step 3 and the change in $\mathrm{R}^{2}$ went up from 0.115 to 0.123 . Effectively, at this stage, the model accounted for $12.3 \%$ of variation on intention to screen for cervical cancer. This change in $\mathrm{R}^{2}$ was significant $\mathrm{R}^{2}=0.153, \mathrm{~F}(6,344)=7.829, \mathrm{p}=0000$.

These results suggest that character identification has a moderating effect on interaction between message frame and intention to screen for cervical cancer. While the change in $\mathrm{R}^{2}$ after the interaction was small, it was statistically significant, implying that character identification has some moderating effect of $15.3 \%$ on the influence of between message frames. One of the reason for the low level effect could be the fact that the current study did not consider sociodemographic homogeneity with story character. The current study used the Igatua (2010) 14 item scale to measure the level of identification with story character which do not consider socio demographic characteristic as a part of character identification.

Other studies that considered other forms of homophily found a bigger moderating effect than did this current study. For example, Hoeken and Sanders (2016) in a study that sought to demonstrate the impact of character identification where they varied story perspective as coming from a lawyer and a medical doctor and observed by law students and medical students, found that professional identification moderated for the acceptance of opinion. In that study, law students were more likely to accept opinion from a lawyer narrator and medical students likely to accept opinions as proposed by a medical doctor.

Similar suggestions were made by Dessart et al. (2018) who focused on the role of character identification and character type in the effects of narrative transportation that occur from storytelling ads, where they varied animal and human characters in the advertisement. They found that identification with animal characters was counterproductive in that, by generating higher levels of narrative transportation, storytelling video ads can reduce character identification, which results in an overall decrease in positive attitude toward the brand, when using animal characters. These findings, therefore, suggest the importance of considering homogeneity of story 
character when using narrative messages to encourage adoption of a health behaviour.

Hoz: Character identification has no significant moderating effects on narrative perspective in regard to screening for cervical cancer among women in the agricultural sector in Kiambu County, Kenya.

To investigate the moderating effects of character identification on narrative perspective, a hierarchical multiple regression analysis was performed. The outcome variable of analysis was intention to screen for cervical cancer, the predictor variable was narrative perspective and the moderator variable evaluated for the analysis was character identification. Moreover, social demographic characteristics variables and message frame were controlled for in the model.

To achieve this, sociodemographic and message frame variables were entered in block 1 , narrative perspective in block 2 , and interaction term between the message frame and character identification entered in block 3 . The results were as indicated in the multiregression table 3 below.

\begin{tabular}{|c|c|c|c|c|c|c|}
\hline Variable & $\beta$ & $t$ & $\mathrm{sr}^{2}$ & $\mathrm{R}$ & $\mathrm{R}^{2}$ & $\Delta \mathrm{R}^{2}$ \\
\hline Step 1 & & & & 0.339 & 0.115 & 0.115 \\
\hline age & .189 & -.559 & -.30 & & & \\
\hline Religion of the respondents & 1.28 & 1.870 & 0.101 & & & \\
\hline Education level & 1.82 & -6.079 & -.025 & & & \\
\hline Marital status & 0.182 & 0.081 & -.085 & & & \\
\hline Message frame & 1.91 & -6.079 & -.314 & & & \\
\hline Step 2 & & & & 0.452 & 0.204 & 0.09 \\
\hline age & 1.38 & 0.428 & -.023 & & & \\
\hline Religion of the respondents & 1.21 & 1.723 & .094 & & & \\
\hline Education level & 0.135 & -0.366 & -.020 & & & \\
\hline Marital status & 0.296 & -1.088 & -.059 & & & \\
\hline Message frame & -1.876 & -6.261 & -.323 & & & \\
\hline Narrative perspective & 5.376 & 6.160 & 0.319 & & & \\
\hline Step 3 & & & & .483 & .233 & 0.029 \\
\hline age & -.117 & -.365 & -.018 & & & \\
\hline Religion of the respondents & 1.108 & 1.705 & .083 & & & \\
\hline Education level & -.151 & -4.09 & -.020 & & & \\
\hline Marital status & -.317 & -1.167 & -.057 & & & \\
\hline Message frame & -1.842 & -1.167 & -.298 & & & \\
\hline
\end{tabular}


Narrative perspective

$\mathrm{NP}^{*}$ character ID Interaction term $=$ narrative rationality and character identification interaction term

Note ${ }^{*} \mathrm{NR}^{*}$ character ID Interaction term $=$ narrative rationality and character identification interaction term

The socio demographic and message frame variables entered in the first step accounted for $11.5 \%$ of variation on intention to screen for cervical cancer. This change was significant $\left(\mathrm{R}^{2}=0.115, \mathrm{~F}(344)=8.74, \mathrm{p}=0.00\right.$. Adding narrative perspective to the model the change in $\mathrm{R}^{2}$ went up from 0.115 to 0.204 . At step 2 , the model, therefore, accounted for $204 \%$ of variation intention to screen for cervical cancer. This change was significant $\left(\mathrm{R}^{2}=0.204, \mathrm{~F}(5,339)=14.413, \mathrm{p}=0000\right)$. The interaction term was added at step 3 and the change in $\mathrm{R}^{2}$ went up from 0.19 to 0.233 . Effectively, at this stage, the model accounted for $23.3 \%$ of variation on intention to screen for cervical cancer. This change in $\mathrm{R}^{2}$ was significant $\mathrm{R}^{2}=0.029, \mathrm{~F}(6,344)=12.643, \mathrm{p}=0000$. These results suggest that character identification has a moderating effect on interaction between message frame and intention to screen for cervical cancer.

A number of studies have demonstrated that first person perspective narrative is more effective than third person perspective. For instance, a study by Kaufman and Libby (2012) found that a first-person narration of experience led to an increased adoption of behaviour compared to the third person narration of the similar experience. Moreover, in another study by Nan et al. (2015), it was found that a firstperson news story about HPV vaccination was more effective in inducing perceived risk of getting HPV than a third-person news story. Similar conclusions were arrived at in the review of studies within the field of health communication suggesting that first-person narratives were more influential than third-person narratives in health decisions (Winterbottom et al., 2008). Furthermore, a study of narrative perspective by de Graaf and colleagues (2012) found that participants identified with a character more when the narrative was told from that character's perspective. The increased identification then resulted in more story-consistent attitudes.

While there are commonalities of these findings how this works has not be well explained. These findings in the current study that identification with story character has effects on interaction between narrative perspective and intention to screen for cervical cancer may explain this. In other words, the current study findings that character identification has a moderating effect on message acceptance in relation to intention to screen for cervical cancer among the respondents, may help explain why first person perspective is more effective than third person perspective. Indeed, this was the suggestion by a study by Nan et al. (2015). According to (Cohen, 2001), 
identification represents a "mechanism through which audience members experience reception and interpretation of the narrative from the inside, as if the events were happening to them" (page, 245). Accordingly, individuals who identify with a character in a narrative are more likely to align their own beliefs and normative expectations with those of the character.

These findings on the moderating role of the character identification on narrative perspective seem to support this assertion by Cohen (2001). In this study, a PostHoc analysis of the mean intention to screen for cervical cancer between the first person and second person perspective narratives showed that the mean scores on th e intention to screen for cervical cancer for respondents who watched the first perso $n$ narrative video clip $(M=26.5,8.7 S D)$, which was greater than that of respondents who watched the second person perspective nnarrative video clip ( $M=20.8$, 8.03SD). Consequently, these findings suggest that a narrative told from a first-person perspective could have resulted in higher identification with the character, which should then lead to greater persuasiveness of the narrative.

Ho3: Character identification has no significant moderating effect on narrative rationality in regard to screening for cervical cancer among women in agricultural sector in Kiambu County, Kenya.

To investigate the moderating effect of character identification on narrative rationality, a hierarchical multiple regression analysis was performed. The outcome variable of analysis was intention to screen for cervical cancer, the predictor variable for the analysis was narrative rationality, and the moderator variable evaluated for in the analysis was character identification. Moreover, social demographic variables, message frame, and narrative perspective were controlled were controlled for in the model.

In block 1, the socio-demographic variables, message frame and narrative perspective were entered then narrative rationality was entered. Then narrative rationality was entered in block 2 . Finally the interaction term between the narrative rationality and character identification were entered in block 3 . The results were as indicated in the multi-regressional table 4 below.

$\begin{aligned} & \text { Table } 4 \text { Hierarchical Multiple Regression analysis of moderating effects of character } \\ & \text { identification on narrative rationality }\end{aligned}$
$\begin{array}{llllrrrr}\text { Variable } & \beta & & \mathrm{t} & \mathrm{sr}^{2} & \mathrm{R} & \mathrm{R}^{2} & \Delta \mathrm{R}^{2} \\ \text { Step 1 } & & & & & \mathbf{0 . 4 5 2} & \mathbf{0 . 2 0 5} & \mathbf{0 . 2 0 5} \\ & 1.38 & 0.428 & -.023 & & & \\ \text { age } & 1.21 & 1.723 & .094 & & & \\ \text { Religion of the respondents } & & & & & & \end{array}$




\begin{tabular}{|c|c|c|c|c|c|c|}
\hline Education level & 0.135 & 0.366 & - & & & \\
\hline Marital status & 0.296 & 1,088 & -059 & & & \\
\hline Message frame & 1.876 & -6.261 & -.323 & & & \\
\hline \multirow[t]{2}{*}{ Narrative perspective } & 5.376 & 6.160 & 0.319 & & & \\
\hline & & & Step 2 & 0.501 & 0.251 & 0.047 \\
\hline age & -0.214 & 0.690 & -.031 & & & \\
\hline Religion of the respondents & 1.087 & 1.729 & 0.075 & & & \\
\hline \multirow[t]{2}{*}{ Education level } & 0.33 & -0.093 & - & & & \\
\hline & & & 0.001 & & & \\
\hline \multirow[t]{2}{*}{ Marital status } & 0.296 & -1.088 & - & & & \\
\hline & & & 0.037 & & & \\
\hline Message frame & -.1501 & -5.014 & -.194 & & & \\
\hline Narrative perspective & 5.377 & 6.392 & .310 & & & \\
\hline \multirow[t]{2}{*}{ Narrative rationality } & 4.267 & 4.915 & .216 & & & \\
\hline & & & Step 3 & 0.503 & 0.253 & 0.002 \\
\hline age & -.187 & -.598 & -.028 & & & \\
\hline Religion of the respondents & 1.011 & 1.597 & .076 & & & \\
\hline Education level & -0.025 & -.070 & -.003 & & & \\
\hline Marital status & 0.222 & -.837 & -.040 & & & \\
\hline Message frame & -1.284 & 0.318 & -.191 & & & \\
\hline Narrative perspective & 5.519 & 6.532 & .309 & & & \\
\hline Narrative rationality & 0.199 & 1.748 & .083 & & & \\
\hline $\begin{array}{l}{ }^{*} \mathrm{NR}^{*} \text { character ID Interaction term }= \\
\text { narrative rationality and character } \\
\text { identification interaction term }\end{array}$ & 0.003 & .899 & .043 & & & \\
\hline
\end{tabular}

${ }^{*} \mathrm{NR}^{*}$ character ID Interaction term $=$ narrative rationality and character identification interaction term

The sociodemographic, message frame, and narrative perspective variables entered in the first step accounted for $20.5 \%$ of variation on intention to screen for cervical cancer. This change was significant $\left(R^{2}=0.2058, F(6,344)=14.41, p=0.00\right.$. Adding narrative rationality to the model changed the R2 from 0.205 to 0.251 . At step 2, the model, therefore, accounted for $25.1 \%$ of intention to screen for cervical cancer. This change was significant $R^{2}=0.0 .251, F(7,344)=16.05, p=0000$.

The interaction term was added at step 3 and the change in $\mathrm{R}^{2}$ went up from 0.251 to 0.253 . Effectively, at this stage, the model accounted for $25.3 \%$ of variation on intention to screen for cervical cancer. This change in $R^{2}$ was not significant $\left(R^{2}=\right.$ 0.253). However, the overall model was significant $F(8,344)=14.13, p=0000$. These 
results suggest that character identification has a moderating effect on interaction between narrative rationality and intention to screen for cervical cancer.

The current study used the Yale (2013) believability scale to measure narrative rationality. A post hoc analysis of the intention to screen for cervical cancer among the respondents revealed that respondents who evaluated the narrative as rational had a higher intention to screen for cervical cancer mean score (M=26.5, 8.06 SD) than those who evaluated the narrative as irrational (21.1, 8.8 SD). Out of those who evaluated narrative as rational, $59.2 \%$ also identified with the character in the story, compared to $40.8 \%$ who evaluated the story as rational but did not identify with the story character.

These findings suggest that where a narrative is rational, story observers also to tend to identify with the story character more. The findings are consistent with findings of other studies that sought to explain the mechanism through which this happens. For example, accordingly Cohen (2001), individuals who identify with a character in a narrative are more are also likely to have believed the story. This makes them more likely to align their own beliefs and normative expectations with those of the character. Moreover, there is evidence that identifying with the character can have effects on the narrative observer's real life in changing their attitudes, and beliefs (Lin, 2017).

Additionally, Igartua (2012) found that identification with character in movies had a significant effect on the audience beliefs (Igartua, 2012). Furthermore, study by Caputo and Rouner (2011) found that identification with character help to reduce social distance with patient who have mental illnesses (Caputo and Rouner, 2011)

\section{Conclusion}

The study found that character identification with story character moderated for all the independent variables. As such, the study concluded that while using narrative messages to promote health behaviour, use of story characters which the target audience can identify with, may help in increasing adoption of advocated health behaviour. Moreover, the study found that the first person perspective was more effective compared with the second person perspective. Consequently, these findings suggest that a narrative told from a first-person perspective could have resulted in higher identification with the character, which should then lead to greater persuasiveness of the narrative

\section{References}

Ahmed, R., \& Bates, B. R. (Eds.). (2016). Health communication and mass media: an integrated approach to policy and practice. Routledge. 
Baussano, I., \& Bray, F. (2019). Modelling cervical cancer elimination. The Lancet Public Health, 4(1), e2-e3.

Bolarinwa, O. A. (2015). Principles and methods of validity and reliability testing of questionnaires used in social and health science researches. Nigerian Postgraduate Medical Journal, 22(4), 195.

Bruni, L., Albero, G., Serrano, B., Mena, M., Gomez, D., \& Munoz, J. (2018). Kenya: Human Papillomavirus and related cancers, Fact Sheet 2018.

Buskwofie, A., David-West, G., \& Clare, C. A. (2020). A review of cervical cancer: incidence and disparities. Journal of the National Medical Association.).

Caputo, N. M., \& Rouner, D. (2011). Narrative processing of entertainment media and mental illness stigma. Health communication, 26(7), 595-604.

Clerici, C. A., Veneroni, L., Bisogno, G., Trapuzzano, A., \& Ferrari, A. (2012). Videos on rhabdomyosarcoma on YouTube: an example of the availability of information on pediatric tumors on the web. Journal of pediatric hematology/oncology, 34(8), e329-e331.

Cohen, D., \& Prusak, L. (2001). In good company (p. 94). Boston: Harvard Business School Press.

Cohen, J. (2001). Defining identification: A theoretical look at the identification of audiences with media characters. Mass communication \& society, 4(3), 245-264.

Cohen, J. (2006). Audience identification with media characters. Psychology of entertainment, 13, 183-197.

Connelly, L. M. (2008). Pilot studies. Medsurg Nursing, 17(6), 411.

D'Alessandro, U. (2012). A phase 3 trial of RTS, S/AS01 malaria vaccine in African infants

Dainton, M., \& Zelley, E. D. (2017). Applying communication theory for professional life: A practical introduction. Sage publications.

De Graaf, A., Hoeken, H., Sanders, J., \& Beentjes, J. W. (2012). Identification as a mechanism of narrative persuasion. Communication research, 39(6), 802-823.

de Martel, C., Plummer, M., Vignat, J., \& Franceschi, S. (2017). Worldwide burden of cancer attributable to HPV by site, country and HPV type. International journal of cancer, 141(4), 664-670.

Denny, L. (2015). Control of cancer of the cervix in low-and middle-income countries. Annals of surgical oncology, 22(3), 728-733.

Dessart, L. (2018). Do ads that tell a story always perform better? The role of character identification and character type in storytelling ads. International Journal of Research in Marketing, 35(2), 289-304.

Diekman, A. B., Gardner, W. L., \& McDonald, M. (2000). Love means never having to be careful: The relationship between reading romance novels and safe sex behaviour. Psychology of Women Quarterly, 24(2), 179-188. 
Elbert, S. P., Dijkstra, A., \& Rozema, A. D. (2017). Effects of tailoring ingredients in auditory persuasive health messages on fruit and vegetable intake. Psychology $\mathcal{E}$ Health, 32(7), 781-797.

Elbert, S. P., Dijkstra, A., \& Rozema, A. D. (2017). Effects of tailoring ingredients in auditory persuasive health messages on fruit and vegetable intake. Psychology $\mathcal{E}$ Health, 32(7), 781-797.

Ferlay, J., Colombet, M., Soerjomataram, I., Mathers, C., Parkin, D. M., Piñeros, M., ... \& Bray, F. (2019).

Estimating the global cancer incidence and mortality in 2018: GLOBOCAN sources and methods. International journal of cancer, 144(8), 1941-1953.

Frank, L. B., Murphy, S. T., Chatterjee, J. S., Moran, M. B., \& Baezconde-Garbanati, L. (2015). Telling stories, saving lives: creating narrative health messages. Health communication, 30(2), 154-163.

Fukuda, Y., Umezaki, M., Nakamura, K., \& Takano, T. (2005). Variations in societal characteristics of spatial disease clusters: examples of colon, lung and breast cancer in Japan. International Journal of Health Geographics, 4(1), 16.

George, D., \& Mallery, P. (2019). IBM SPSS Statistics 26 step by step: A simple guide and reference. Routledge.

Green, M. C. (2008). Research Challenges: Research challenges in narrative persuasion. Information Design Journal, 16(1), 47-52.

Green, M. C., \& Brock, T. C. (2002). In the mind's eye: Transportation-imagery model of narrative persuasion.

Gultekin, M., Ramirez, P. T., Broutet, N., \& Hutubessy, R. (2020). World Health Organisation call for action to eliminate cervical cancer globally.

Hartling, L., Scott, S., Pandya, R., Johnson, D., Bishop, T., \& Klassen, T. P. (2010). Storytelling as a communication tool for health consumers: development of an intervention for parents of children with croup. Stories to communicate health information. BMC pediatrics, 10(1), 64.

Healey, P., Stager, M. L., Woodmass, K., Dettlaff, A. J., Vergara, A., Janke, R., \& Wells, S. J. (2017). Cultural adaptations to augment health and mental health services: a systematic review. BMC health services research, 17(1), 8 .

Hinyard, L. J., \& Kreuter, M. W. (2007). Using narrative communication as a tool for health behaviour change: a conceptual, theoretical, and empirical overview. Health Education \& Behaviour, 34(5), 777-792.

Hoeken, H., \& Geurts, D. (2005). The influence of exemplars in fear appeals on the perception of self-efficacy and message acceptance. Information Design Journal $\mathcal{E}$ Document Design, 13(3).

homas, W. S. (2016). Voluntary Control of Desire. Open Journal of Philosophy, 6(01), 103-109. 
Hunsaker, A., \& Hargittai, E. (2018). A review of Internet use among older adults. New Media \& Society, 20(10), 3937-3954.

Igartua, J. J. (2010). Identification with characters and narrative persuasion through fictional feature films. Communications, 35(4), 347-373.

Jiang, S., \& Street, R. L. (2017). Pathway linking Internet health information seeking to better health: a moderated mediation study. Health Communication, 32(8), 1024-1031.

Jones, B. (2011). Mixed uptake of social media among public health specialists. World Health Organisation. Bulletin of the World Health Organisation, 89(11), 784.

Kannisto, K. A., Koivunen, M. H., \& Välimäki, M. A. (2014). Use of mobile phone text message reminders in health care services: a narrative literature review. Journal of medical Internet research, 16(10), e222.

Kaufman, G. F., \& Libby, L. K. (2012). Changing beliefs and behaviour through experience-taking. Journal of personality and social psychology, 103(1), 1.

Kelly, M. P., \& Barker, M. (2016). Why is changing health-related behaviour so difficult?. Public health, 136, 109-116.

Kumar, S., Kumar, N., \& Vivekadhish, S. (2016). Millennium development goals (MDGS) to sustainable development goals (SDGS): Addressing unfinished agenda and strengthening sustainable development and partnership. Indian journal of community medicine: official publication of Indian Association of Preventive \& Social Medicine, 41(1), 1.

Lee, E., \& Leets, L. (2002). Persuasive storytelling by hate groups online: Examining its effects on adolescents. American behavioural scientist, 45(6), 927-957.

Lim, J. N., \& Ojo, A. A. (2017). Barriers to utilisation of cervical cancer screening in Sub Sahara Africa: a systematic review. European journal of cancer care, 26(1), e12444.

Louie, K. S., De Sanjose, S., Diaz, M., Castellsague, X., Herrero, R., Meijer, C. J., \& Bosch, F. X. (2009). Early age at first sexual intercourse and early pregnancy are risk factors for cervical cancer in developing countries. British journal of cancer, 100(7), 1191-1197.Louie et al., 2009, Rodríguez et al., 2017

Luszczynska, A., Cao, D. S., Mallach, N., Pietron, K., Mazurkiewicz, M., \& Schwarzer, R. (2010). Intentions, planning, and self-efficacy predict physical activity in Chinese and Polish adolescents: Two moderated mediation analyses. International Journal of Clinical and Health Psychology, 10(2), 265-278.

Massi Lindsey, L. L., \& Ah Yun, K. (2005). The relationship between narrative content variation, affective and cognitive reactions, and a person's willingness to sign an organ donor card. Communication Research Reports, 22(4), 253-263.

Meisel, Z. F., Metlay, J. P., Sinnenberg, L., Kilaru, A. S., Grossestreuer, A., Barg, F. K., ... \& Perrone, J. (2016). A randomised trial testing the effect of narrative 
vignettes versus guideline summaries on provider response to a professional organisation clinical policy for safe opioid prescribing. Annals of emergency medicine, 68(6), 719-728

Morema, E. N., Atieli, H. E., Onyango, R. O., Omondi, J. H., \& Ouma, C. (2014). Determinants of cervical screening services uptake among $18-49$ year old women seeking services at the Jaramogi Oginga Odinga Teaching and Referral Hospital, Kisumu, Kenya. BMC health services research, 14(1), 335.

Morgan, C., Cira, M., Karagu, A., Asirwa, F. C., Brand, N. R., Lunsford, N. B., ... \& Loehrer, P. J. (2018).

The Kenya cancer research and control stakeholder program: Evaluating a bilateral partnership to strengthen national cancer efforts. Journal of cancer policy, 17, 3844.

Moshi, F. V., Vandervort, E. B., \& Kibusi, S. M. (2018). Cervical Cancer Awareness among Women in Tanzania: an analysis of data from the 2011-12 Tanzania HIV and Malaria Indicators Survey. International journal of chronic diseases, 2018.

Nan, X., Dahlstrom, M. F., Richards, A., \& Rangarajan, S. (2015). Influence of evidence type and narrative type on HPV risk perception and intention to obtain the HPV vaccine. Health communication, 30(3), 301-308.

Nordfeldt, S., Hanberger, L., \& Berterö, C. (2010). Patient and parent views on a Web 2.0 Diabetes Portal-the management tool, the generator, and the gatekeeper: qualitative study. Journal of medical Internet research, 12(2), e17.(D'Alessandro, Peltier, \& Dahl, 2012) .

orema, Atieli, Onyango, Omondi, \& Ouma, 2014a

Palacio-Mejía, L. S., Rangel-Gómez, G., Hernández-Avila, M., \& Lazcano-Ponce, E. (2003). Cervical cancer, a disease of poverty: mortality differences between urban and rural areas in Mexico. Salud pública de méxico, 45, 315-325

Pimenta, J. M., Galindo, C., Jenkins, D., \& Taylor, S. M. (2013). Estimate of the global burden of cervical adenocarcinoma and potential impact of prophylactic human papillomavirus vaccination. BMC cancer, 13(1), 553.

Quattrin, R., Filiputti, E., \& Brusaferro, S. (2015). Health promotion campaigns and mass media: Looking for evidence. Primary Health Care, 5(190), 2167-1079.

Reinhart, A. M., Marshall, H. M., Feeley, T. H., \& Tutzauer, F. (2007). The persuasive effects of message framing in organ donation: The mediating role of psychological reactance. Communication Monographs, 74(2), 229-255.

Rice, R. E., \& Atkin, C. K. (Eds.). (2012). Public communication campaigns. SAGE publications.

Rogers, M. A., Lemmen, K., Kramer, R., Mann, J., \& Chopra, V. (2017). Internetdelivered health interventions that work: systematic review of meta-analyses 
and evaluation of website availability. Journal of medical Internet research, 19(3), e90.

Russell, M., Chen, M. J., Nochajski, T. H., Testa, M., Zimmerman, S. J., \& Hughes, P. S. (2009). Risky sexual behaviour, bleeding caused by intimate partner violence, and hepatitis $C$ virus infection in patients of a sexually transmitted disease clinic. American journal of public health, 99(S1), S173-S179.

Sherer, M., Maddux, J. E., Mercandante, B., Prentice-Dunn, S., Jacobs, B., \& Rogers, R. W. (1982). The self-efficacy scale: Construction and validation. Psychological reports, 51(2), 663-671.

Slater, M. D., \& Rouner, D. (2002). Entertainment-education and elaboration likelihood: Understanding the processing of narrative persuasion. Communication theory, 12(2), 173-191.

Slater, M. D., Rouner, D., \& Long, M. (2006). Television dramas and support for controversial public policies: Effects and mechanisms. Journal of Communication, 56(2), 235-252.

Stitt, C. R., \& Nabi, R. (2005). The persuasive impact of narratives: A comparison across message types and modalities. Information Systems Division of the annual International Communication Association, New York.County Annual Development plan (2019),

Strasser, R., Kam, S. M., \& Regalado, S. M. (2016). Rural health care access and policy in developing countries. Annual review of public health, 37, 395-412.

Sukalla, F., Wagner, A. J., \& Rackow, I. (2017). Health Communication I Dispelling Fears and Myths of Organ Donation: How Narratives Including Information Reduce Ambivalence and Reactance. International Journal of Communication, 11, 21.

Sukalla, F., Wagner, A. J., \& Rackow, I. (2017). Health Communication I Dispelling Fears and Myths of Organ Donation: How Narratives Including Information Reduce Ambivalence and Reactance. International Journal of Communication, 11, 21.

Walsh-Childers, K. (2016). Mass media and health: examining media impact on individuals and the health environment. Routledge.

Winterbottom, Anna, Hilary L. Bekker, Mark Conner, and Andrew Mooney. "Does narrative information bias individual's decision making? A systematic review." Social science \& medicine 67, no. 12 (2008): 2079-2088.

Witte, K. (1996). Predicting risk behaviours: Development and validation of a diagnostic scale. Journal of health communication, 1(4), 317-342.

Wojcieszak, M., \& Kim, N. (2016). How to improve attitudes toward disliked groups: The effects of narrative versus numerical evidence on political persuasion. Communication Research, 43(6), 785-809. 
Yale, R. N. (2013). Measuring narrative believability: Development and validation of the Narrative Believability Scale (NBS-12). Journal of Communication, 63(3), 578-599.

Yoo, J. H., Kreuter, M. W., Lai, C., \& Fu, Q. (2014). Understanding narrative effects: The role of discrete negative emotions on message processing and attitudes among low-income African American women. Health communication, 29(5), 494-504.

Yoon, H. J., \& Kim, Y. J. (2016). Understanding green advertising attitude and behavioural intention: An application of the health belief model. Journal of promotion management, 22(1), 49-70. 